The Adoption of Standard Time in France.-To la Nature (No. I970) M. H. Cathenod contributes an interesting illustrated article on the international system of standard time, to which France has now given its support. $\mathrm{He}$ outlines the history of its general adoption, the reasons for accepting the Greenwich meridian as the basis of the system, and the reasons for France's hesitation in entering the international agreement earlier. The article is usefully illustrated by a number of sketch-maps, and, in concluding it, M. Cathenod reiterates M. Faye's hope that, in return for the international adoption of the Greenwich meridian as the point of departure, Great Britain will favour the unification of the system of weights and measures by adopting the metrical system.

The Different Forms of Halos and their ObservaTION.-Although a large number of famous astronomers and other observers have ditected their attention to the halos which are to be seen from time to time surrounding the sun or moon, these phenomena still present some unsolved problems. In the March number of L'Astronomie Dr. Besson, of the Montsouris Observatory, suggests that the observations should be made regularly by amateurs, for the phenomena are visible without the help of instruments; but the amateur often lacks the knowledge of what to look for and what is worth recording. To remedy this state of affairs, he gives some excellent descriptions and instructions well illustrated by numerous diagrams.

Two of these diagrams show the solar halo of $22^{\circ}$, the halo of $46^{\circ}$, the upper and lower tangential arcs, the parhelia and anthelia, the oblique arcs and the luminous column and the arcs of Lowitz. Each phenomenon is then described and discussed, so that the observer may know when and where he may expect to see it, and what colours, if any, should attend it. Special notes and a diagram are given for the circumzenithal arcs; which are not so frequently seen, and generally last not longer than five minutes. M. Besson finds that the observations published in late years favour the theory of Bravais as to the appearance of these arcs, a theory which Pernter did not accept. This article is to be followed by another, in which the author will describe some of the rarely seen and abnormal phenomena which attend the apparitions of halos.

Nova Lacerta.-In an article which appears in No. 9, vol. civ., of The Scientific American, Prof. S. A. Mitchell gives some very interesting facts concerning the apparition of Nova Lacertæ and the discovery and nature of novæ in general. Since the first recorded nova, that of Hipparchus in the year I34 B.C., only thirty-six new stars have been observed, and of these eighteen have been discovered since $\mathrm{I} 885$; fifteen of these have been first found on photographs, and, of the fifteen, fourteen were discovered at the Harvard College Observatory from plates taken there or at Arequipa.

The photographs of Nova Lacertæ taken by Profs. Barnard and Wolf show that between November ig and 23, 1910, the light. of the star increased 400o-fold. A spectrum secured by Prof. Frost, using the 40-inch refractor at the Yerkes Observatory on January 3, is stated to be exactly analogous to those of Nova Aurigæ and Nova Persei, so that any explanation which accounts for their peculiarities will also explain Nova Lacertæ. Prof. Mitchell discusses, very briefly and generally, the causes which may produce novæ, and shows that the "pressure" theory and the "collision" theory leave much to be explained; he rather favours the passage of a rapidly moving star through a previously unknown nebula. The article is well illustrated, the reproductions including photographs of the Harvard College observatories at Cambridge (Mass.) and at Arequipa.

The Star List of the American Ephemeris, igir.For thirty years (1882-19ri) the star list of the American Ephemeris has given ten-day ephemerides for the apparent places of some 378 especially chosen stars, and daily ephemerides for five circumpolar stars. The need of a larger and improved star list for the use of astronomers, engineers, and surveyors prompted the issue, in 1908, of the list of 780 stars for 1909 , and the present issue is similar to that except that forty-five more stars have been added. As the Ephemeris for ror 2 contains a list identical with the present issue, the publication of a separate Star List will not be continued.

$$
\text { No. } 2 \text { I6I, VOL. 86] }
$$

EPHEMERIS FOR WOLF'S COMET.-In No. 4483 of the Astronomische Nachrichten, M. Kamensky continues his ephemeris for Wolf's comet, which may return to perihelion in February next. At present the comet is apparently in Aquila, about half-way between $\delta$ Aquilæ and $\eta$ Serpentis, and is moving in a north-easterly direction; its calculated magnitude is about $\times 4$.

\section{ANTARCTIC EXPEDITIONS}

$\mathrm{THE}$ centre of interest in polar exploration has been shifted, earlier than might have been expected, from the north to the south by the telegram forwarded from Stewart Island from the returning Terra Nova. This vessel has carried Captain Scott's expedition to its base successfully in spite of encountering heavy pack-ice in the remarkabiy low latitude of $65^{\circ} \mathrm{S}$., and having to make 380 miles of difficult travelling through it. The telegram includes messages from Captain Scott and from Lieut. Pennell, the officer commanding the Terra Nova on her return, and it is in the latter message that the salient point of interest is found, namely, the discovery of the celebrated Fram, with Captain Amundsen's expedition aboard, already established in the Bay of Whales, an inlet in the ice-barrier at $165^{\circ} \mathrm{W}$. long. It is perhaps early as yet to account for Amundsen's change of plan (for he originally sailed ostensibly with an Arctic journey in view) the interest of the moment is that, assuming his base to be established at the Bay of Whales, he is nearer the Pole by nearly 'roo miles' than Scott if he elects to strike south in a direct line, and risk discovering a new route up to the polar plateau. If, however, he makes for Shackleton's known route (which Scott, of course, will follow) up the Beardmore glacier, he will have little if any advantage in distance.

Some uncertainty as to Scott's arrangements is caused by the messages. His own states that after leaving him at the base in McMurdo Sound the Terra Nova would leave a geological party on Victoria Land, and then proceed to leave an exploring party on King Edward Land. As a fact, it appears that the Terra Nova proceeded along the ice-barrier towards King Edward Land first, failed to make a landing at Cape Colbeck, and returned to the Bay of Whales. Here the Fram was found, and here two interpretations have been put upon the message:-" The Fram is proceeding to Buenos Aires, returning the following season to re-embark Captain Amundsen. Stores were landed and a hut erected two miles from the ship, and the Terra Nova afterwards left again for McMurdo Sound."

Some commentators refer the stores and hut to the party from the Terra Nova, which seems the more probable on the face of the sentence; others suspect wrong paragraphing, and suppose the stores and hut to belong to Amundsen's party. Later the ship was driven north, and landed the "eastern" party at Cape Adare (Victoria Land), which would suggest that the second group of commentators are right, and leaves it uncertain as to what has become of the geologists. This will doubtless be cleared up when the ship reaches another cable station; in the meantime, it seems reasonable to hope that there will be room in Victoria $\mathrm{I}_{q}$ and for Scott's party (especially if they are geologists only) and the expedition of Dr. Mawson, who has expressed some doubt as to the inviolability of his province.

Scott, Amundsen, and Mawson (who will have as commander Captain J. K. Davis, late of the Nimrod) do not exhaust the list of those already attacking or intending to attack the problems of the south. A Japanese expedition under Lieut. N. Shirase, having little in common with European equipment beyond a characteristic determination, was reported to have left for the south at the end of last year. Nor is it certain that an American expedition has been given up, in spite of Commander Peary's determination not to lead it, for it is stated that his captain, Bartlett, is ready to take his place.

It may be added that already Scott's expedition has added something to scientific knowledge, for those returning on the Terra Nova have carried the north coast of Victoria Land (by distant sights) some I50 miles beyond its previously known extension, and the interesting feature of an open sea immediately south of the Balleny Islands was encountered. 